\title{
INVENTORY MODELS INVOLVING LEAD TIME Crashing Cost as AN EXPONENTIAL FunCTION
}

\author{
M. Vijayashree ${ }^{1 *}$, R. Uthayakumar ${ }^{2}$ \\ ${ }^{1 *}$ Full Time Research Scholar, Department of Mathematics, The Gandhigram Rural \\ Institute - Deemed University, Gandhigram- 624 302, Tamilnadu, India. \\ ${ }^{2}$ Professor \& Head, Department of Mathematics, The Gandhigram Rural Institute - \\ Deemed University, Gandhigram- 624302, Tamilnadu, India.
}

\begin{abstract}
Inventory management and control is concerned with the acquisition and storage of materials required for supporting various business operations. Lead time reduction is another important production activity in an integrated inventory control. Lead time plays a vital role and has been a topic of interest for many authors in inventory organization.

Lead time is a necessary aspect in any supply chain management and inventory management system. The time gap between placing of an order and its actual arrival in the inventory is known as lead time. In most of the literature dealing with inventory problems, either in deterministic or probabilistic model, lead time is viewed as a prescribed constant or a stochastic variable, which therefore, is not subject to control. But, in numerous sensible circumstances, lead time can he reduced by an additional crashing cost; in other words, it is controllable, so in this article, we have considered the lead time crashing cost is an exponential function of lead time. A solution procedure is developed to find the optimal solution.

In this article, both lead time and the order quantity are considered as the decision variables. The behaviour of the model is presented graphically. The result is illustrated with the help of a numerical example. Finally, Graphical representation is presented to illustrate the model. The solution procedure with the help of the software Matlab 2008 is furnished to determine the optimal solution.
\end{abstract}

Keywords: Integrated inventory model, Supply chain management, lead time crashing cost

Subject Classification Code: 90B05, 90C25, 90C30.

*Corresponding author

Tel.: +91-451-2452371, Fax: 91-451-2453071

\section{INTRODUCTION}

Inventory control is significant in supply chain management. In current years, the majority inventory problems have focused on the integration between the supplier and the retailer. The integrated inventory model has become more and more important, because the supplier and the retailer wish to increase their mutual benefit; therefore, they endeavour to form a strategic alliance in order to minimize their own cost or maximize their own profit, and then the trading parties can collaborate and share information to achieve improved benefits. This implies that the optimal contract quantity and number of deliveries must be determined at the outset of the contract based on their integrated total cost function. 
Gholami-Qadikolaei et al. [10] have summarised the number of advantages and benefits has been associated in the efforts of control of the lead time (which is a goal of JIT inventory management philosophies that emphasizes high quality and keeps low inventory level and lead time to a practical minimum). The benefits of JIT purchasing include small lot sizes, frequent deliveries, consistent high quality, reduction in lead times, decrease in inventory levels, lower setup cost and ordering cost, and close supplier ties. In recent years, companies have found that there are substantial benefits from establishing a long-term sole-supplier relationship with supplier Martinich [24]. In the JIT environment, a close cooperation exists between supplier and purchaser to solve problems together, and thus maintains stable, long-term relationships.

Among the modern production management, the Japanese successful experiences of using JustIn-Time (JIT) production show that the advantages and benefits associated with the efforts to control the lead-time can be clearly perceived. The goal of JIT inventory management philosophies is the focus that emphasizes high quality, keeps low inventory level and lead-time to a practical lowest amount. Shortening the lead time is recognized as the feasible and effective way to achieve the goal of JIT. The objective of JIT inventory management philosophies is the focus which emphasizes high quality, keeps low inventory level and lead time to a practical lowest amount.

Ouyang and $\mathrm{Wu}[33]$ discuss lead time plays a very important role in inventory organization. In most of the literature dealing with inventory problems, either in deterministic or probabilistic model, lead time is viewed as a prescribed constant or a stochastic variable, which therefore, is not subject to control (Naddor[26], Silver and Peterson [41]). In fact, lead time usually consist of the following components (Tersine [43]); order training, order shipment, dealer lead time release time, and setup time. In many practical situations, lead time, we can lower the safety stock, reduce the loss caused by stockout, improve the service level to the customer, and increase the spirited ability in business. Recently, some models considering lead-time as a decision variable have been developed. Liao and Shyu [22] have initiated a study on lead-time reduction by presenting an inventory model in which lead- time is a decision variable and the order quantity is predetermined. Ben-Daya and Raouf [3] developed a model that considered both lead-time and order quantity as decision variables. Later, Ouyang et al. [32] and Ouyang and Wu ([28], [30] and [29]) have generalized the Ben-Daya and Raouf [3] model by considering shortages in which the lead-time demand is measured a normal distribution or distribution free. Later, Moon and Choi [25], Hariga and Ben-Daya [15] have extended the Ouyang et al. [32] model to relax the assumption of a given service level and treat the reorder point as a decision variable. Other papers related to this area are Lan et al. [20], Ouyang and Chuang [29], Ouyang and Chang [27], Pan and Hsiao [34] and others.

Later many researchers (see $[4,6,7,8$, and 9]) developed lead time reduction inventory models under various crashing cost function and practical situations. The underlying assumption in the above studies was that lead time could be decomposed into $\mathrm{n}$ mutually independent components, each with a different but fixed crash cost independent of the lead time. Recently, Hsu and Lee [19] investigated the decisions of replenishment and lead-time reduction for a single manufacturer multiple-retailer integrated inventory system with the assumption of lead time crashing cost is a non-increasing stairstep function of lead time. Later, Yang [47] developed supply chain integrated inventory model with present value and the crashing cost is determined by the length of lead time, which is polynomial form. In contrast to existing inventory models, this paper considers that the crashing cost is an exponential function of lead time. Further, numerical example is provided to illustrate the benefits of integration. 
International Journal of Managing Value and Supply Chains (IJMVSC) Vol. 7, No. 2, June 2016

\section{Literature ReVIEW}

Shukla et al. [40] have talk about the Supply Chain Management (SCM) is a network of facilities that produce raw materials, transform them into intermediate goods and then final products, and deliver the products to customers through a distribution system. The management of the supply chain and the roles of various factors involved differ from industry to industry and company to company.

Supply Chain Management is a network of facilities that produce raw materials, transform them into intermediate goods and then final products, and deliver the products to customers through a distribution system. It spans procurement, manufacturing and distribution (Lee \& Billington [21]) the basic objective of supply chain management is to "optimize performance of the chain to add as much value as possible for the least cost possible". In other words, it aims to link all the supply chain agents to jointly cooperate within the firm as a way to maximize productivity in the supply chain and deliver the most benefits to all related parties (Finch [8] ). Adoption of Supply chain management practices in industries has steadily increased since the 1980s. A number of definitions are proposed and the concept is discussed from many perspectives. However Cousins et al. [7]; Sachan and Datta [38]; Storey et al. [42] provided excellent review on supply chain management literature. These papers define the concept, principals, nature, and development of SCM and indicate that there is an intense research being conducted around the world in this field they critically assessed developments in the theory and practice of supply management.

Sara et al. [39] discuss on the importance of supply chain management has created remarkable interest to make a kind of partnership among supply chain's entities. Traditionally, the buyer and vendor used a policy according to economic order quantity (EOQ) or economic production quantity (EPQ) classical methods. To refine these classical methods, in order to satisfy today's market requirements, the concept of joint economic lot size (JELS) is introduced. In fact, the concept of JELS is a kind of integration between two different business entities to gain competitive advantages and lesser total cost.

Yang and Pan [46] explain the supply chain management is a well-liked practice in manufacturing systems, and just-in-time (JIT) production plays a crucial role in supply chain environments. Companies are using JIT production to gain and maintain a competitive advantage. The characteristics of JIT systems are consistent high quality, small lot sizes, frequent delivery, short lead time, and close supplier ties. Recently, the issue of just-in-time (JIT) manufacturing has received considerable attention, and one of the most interesting topics on this issue is the integration of vendor and buyer in the supply chain system (Chang et al. [5]). Many researchers have shown that improved benefits can be achieved through the coordination of vendor and buyer. Combination between two different business entities is an important way to gain competitive advantages as it lowers the joint total cost of the system. Therefore, in modern enterprises, the integration of vendor-buyer inventory system is an important issue. The coordination between vendor and buyer for improving the performance of inventory control has received a great deal of attention and the integrated approach has been studied for years. Typically, integrated approach focuses on the production-inventory decisions of supply chain partners while minimizing the total relevant cost of the system.

The combination between vendor and buyer for improving the performance of inventory system control has been discussed for years. Goyal [12] was an initiate in studying an integrated inventory model consisting of a vendor and a buyer, who showed a coordinated replenishment policy is more desirable than each party operating its individual optimal policy. The framework proposed by Goyal [12] encouraged many researchers to explore various types of integrated inventory model. Banerjee [2] modified Goyal's [12] model considering finite production rate of 
the vendor, and the vendor produces for the buyer on a lot-for-lot basis. Goyal [12] undisturbed the lot-for-lot policy and suggested that the vendor's economic production quantity should be an integer multiple of the buyer's order quantity. Lu [23] relaxed the assumption of Goyal [13] about completing a production batch before starting shipments and proposed a model which allows shipments to take place during production period also. Subsequently, several other shipment policies (Goyal [14], Hill [17], Hill [18], Goyal and Nebebe [11]) have been proposed to study the single-vendor single- buyer supply chain.

The Japanese experience of using Just-In-Time (JIT) production shows that there are advantages and benefits associated with their efforts to control lead time. Lead time plays an important role and has been a topic of interest for many authors in continuous review inventory system. The replenishment lead time is usually prescribed whether deterministic or probabilistic. However, in many practical situations lead time can be controlled and reduced at an added cost (called crashing cost). The crashing time idea originated in project management where the duration of some activities can be reduced by allocating more resources at an extra direct costs for these activities.

Lead time decrease is an additional important production action in an integrated inventory control. Lead time consists of order preparation, order transmittal, order processing and assembly, additional stock acquisition time and delivery time Ballou [1]. Recently, Ouyang et al. [25] extended the $(\mathrm{Q}, \mathrm{r})$ model by Ben-Daya and Raouf [3] to think the lead time effect and add in the partial backordering into the inventory model. Hariga [16] studied the relationship between lot size and lead time in the process time aspect. Pan and Yang [27] presented an integrated supplierpurchaser model with controllable lead time. The model has a substantial cost saving when lead time is controllable. Chen et al. [6] presented a continuous review inventory model when ordering cost is dependent on lead time. Pan and Yang [35] developed a study of an integrated inventory model with controllable lead time. Ben-Daya and Hariga [4] developed a continuous review inventory model where lead time is considered as a controllable variable. Lead time is decomposed into all its components: set-up time, processing time and non-productive time. Later, (Ouyang et al. [31] extended Pan and Yang's [34] model by allowing shortages. Liao and Shyu [15] state that there is a lack of an appropriate inventory model that treats lead time as a decision variable. These authors have presented a model which can be used to determine the length of lead time that minimizes the expected total relevant cost. Lead time is decomposed into $n$ components each having a different crashing cost for reduced lead time. Consequently, the lead time crashing cost function is described using a piecewise linear function.

Exponential functions demonstrate exponential development (or decompose). This means that the functions moreover rise or go down much more radically than polynomials. In a real surroundings, to reduce lead time, managers may ask workers to work overtime, employ part-time workers, use individual delivery, and so on. Impulsively, a high additional cost should be paid for these services. Therefore, crashing costs were observed to produce with lead time by a quantity which can be approximated by an exponential function of lead time. The best thing about exponential functions is that they are so useful in real world situations. Exponential functions are used to model populations, carbon date artifacts, help coroners determine time of death, compute investments, as well as many other applications.

Ghare and Schrader [9] were the first to develop an EOQ model for an item with exponential decay and constant demand. The certain commodities were observed to shrink with time by a proportion which can be approximated by a negative exponential function of time. In the recent years, Priyan and Uthayakumar [37] have developed Optimal inventory management strategies for pharmaceutical company and hospital supply chain in a fuzzy-stochastic environment. Here the author has been used exponential function of lead time crashing cost. Priyan and Uthayakumar [36] have developed Continuous review inventory model with controllable lead 
International Journal of Managing Value and Supply Chains (IJMVSC) Vol. 7, No. 2, June 2016

time, lost sales rate and order processing cost when the received quantity is uncertain. M.Vijayashree and R Uthayakumar [44] have developed integrated inventory model with controllable lead time involving investment for quality improvement in supply chain system. $\mathrm{M}$. Vijayashree and R Uthayakumar [45] have developed two-echelon supply chain inventory model with controllable lead time, here we have used exponential function of lead time crashing cost. To the best of our knowledge, the author has developed inventory models involving lead time crashing cost as an exponential function. In this model we have considered the lead time crashing cost as an exponential function.

The remainder of this chapter includes the following aspects: Literature review is given in section 2. The primary assumption and notations are provided in section 3. Section 4 describes the mathematical model is developed. The solution procedure is given in the section 5. A numerical example is provided in section 6, to illustrate the results. Finally, conclusion is given in section 7.

\section{NOTATIONS AND ASSUMPTIONS}

To establish the mathematical model, the following notations and assumptions are used as follows

\subsection{Notations}

To develop the proposed model, we adopt the following variables and parameters

$\begin{array}{ll}\text { D } & \text { Demand } \\ \text { Q } & \text { Order quantity } \\ \text { A } & \text { Ordering cost } \\ \text { R } & \text { reorder point } \\ \text { h } & \text { Holding cost } \\ \text { L } & \text { Lead time in weeks } \\ \text { TC } & \text { Total cost }\end{array}$

\subsection{Assumptions}

To develop the proposed model, we adopt the following assumptions

1. The inventory is continuously reviewed. The buyers place an order when the on hand inventory reaches the reorder point $R$.

2. The buyer places an order when the inventory position reaches the reorder point $R$. The reorder point $R=$ expected demand during lead time + safety stock, that is, $R=D L+k \sigma \sqrt{L}$ where $k$ is a safety factor and $\sigma$ is the standard deviation.

3. The demand $X$ during lead time $L$ follows a normal distribution with mean $\mu L$ and standard deviation $\sigma \sqrt{L}$.

4. The extra cost incurred by the vendor will be transferred to the buyer if shortened lead time is requested.

5. If the buyer is not eager to add an extra cost to control the lead time, he can obtain his items exactly on the existing lead time ( $L=L_{e}$ ) and the crashing cost is zero. Otherwise, the lead time $L$ of the buyer should be within the interval $\left[L_{e}, L_{s}\right]$, that is $L_{s} \leq L<L_{e}$. 
6. The crashing costs were experimental to grow with lead time by a proportion which can be approximated by an exponential function. Therefore, the lead time crashing cost per order $R(L)$, is assumed to be an exponential function of $L$ and is defined as

$R(L)=\left\{\begin{array}{ll}0 & \text { if } \mathrm{L}=L_{e} \\ e^{C / L}, & \text { if } L_{s} \leq L<L_{e}\end{array}\right.$ where $C$ is a positive constant. The application of the exponential function lead time crashing cost has been proposed by many authors, for example Vijayashree and Uthayakumar [45] and Priyan and Uthayakumar[36]

\section{Mathematical Model}

Based on the above notations and assumptions, the total cost is given by $T C(Q, L)=$ Ordering cost+ holding cost+ lead time crashing cost.

Since $A$ is the ordering cost per order, the expected ordering cost per year is given by $\frac{A D}{Q}$.

From assumption (2), the reorder point $R=D L+k \sigma \sqrt{L}$, where $k$ is known as the safety factor. If we assume a linear decrease over the cycle, then

$\bar{I}=(Q, r) \cong \frac{Q}{2}+R-D L=\frac{Q}{2}+k \sigma \sqrt{L}$

Lead time crashing cost $R(L)$ is given by $\frac{D}{Q} R(L)$

$$
\begin{gathered}
T C(Q, L)=\frac{A D}{Q}+h\left(\frac{Q}{2}+k \sigma \sqrt{L}\right)+\frac{D}{Q} R(L) \\
=\frac{A D}{Q}+h\left(\frac{Q}{2}+k \sigma \sqrt{L}\right)+\frac{D}{Q} e^{\frac{C}{L}}
\end{gathered}
$$

for $L_{s} \leq L<L_{e}$

\section{SOLUTION PROCEDURE}

Taking the partial derivatives of $T C(Q, L)$ with respect to $Q$ and $L$ in each time interval $L \in\left[L_{e}, L_{s}\right]$ and equating to zero, we obtain

$\frac{\partial T C(Q, L)}{\partial Q}=-\frac{A D}{Q^{2}}+\frac{h}{2}-\frac{D e^{\frac{C}{L}}}{Q^{2}}=0$

$\frac{\partial T C(Q, L)}{\partial L}=\frac{1}{2} h k \sigma L^{\frac{-1}{2}}-\frac{D C e^{\frac{C}{L}}}{Q L^{2}}=0$

Notice that for fixed $L, T C(Q, L)$, is convex in $Q$. (See the appendix) However, for fixed $Q, T C(Q, L)$ is concave in $L \in\left[L_{e}, L_{s}\right]$. Therefore, for fixed $Q$ the minimum occurs at the end points of the interval. From (2), we have 
International Journal of Managing Value and Supply Chains (IJMVSC) Vol. 7, No. 2, June 2016

$Q=\sqrt{\left(\frac{2 D A+2 D e^{\frac{C}{L}}}{h}\right)}$

The above solution procedure can be used to find the optimal $Q$ and $L \in\left[L_{e}, L_{s}\right]$.

For each break point $L \in\left[L_{e}, L_{s}\right]$ compute $Q$ using (4).

Compute the corresponding integrated total cost from equation (1)

The optimal $Q$ and $L \in\left[L_{e}, L_{s}\right]$ will be the values for which the total cost $T C(Q, L)$ is minimum.

\section{NUMERICAL EXAMPLE}

In this section, a numerical example is given to illustrate the above solution procedure. Let us consider the inventory system with the following data $D=600$ units/year, $A=\$ 200$ per order, $\mathrm{h}=20, \sigma=6$ units/week, $\mathrm{k}=2.3$ and lead time crashing cost $R(L)=\left\{\begin{array}{ll}0 & \text { if } \quad \mathrm{L}=6 \\ e^{\frac{C}{L}} & \text { if } \quad 1 \leq L<6\end{array}\right.$ where $C=5$.

Applying the above solution procedure the computational results are presented in table (1). The optimal solutions from table (1) can be read off as lead time $L^{*}=2$ weeks, order quantity $Q^{*}=113$ units and the corresponding integrated total cost $T C^{*}=2647$. A graphical representations is presented to show the convexity of $T C$ in figure (1) and Graphical representation of the optimal solution in figure (2).

Table (1) optimal values for different values of lead time

\begin{tabular}{|l|l|l|l|l|l|l|l|l|l|l|l|l|}
\hline $\mathbf{L}=\mathbf{1}$ & L=2 & L=3 & L=4 & L=5 & \multicolumn{2}{l|}{ L= 6 } \\
\hline \multicolumn{8}{|c|}{$R(L)=e^{\frac{C}{L}}, C=5,1 \leq L<5$} \\
\hline $\mathrm{Q}$ & TC & $\mathrm{Q}$ & TC & $\mathrm{Q}$ & TC & $\mathrm{Q}$ & TC & $\mathrm{Q}$ & TC & $\mathrm{Q}$ & TC \\
\hline 146 & 3168 & 113 & $\mathbf{2 6 4 7}$ & 111 & 2698 & 110 & 2762 & 110 & 2823 & 110 & 2867 \\
\hline
\end{tabular}




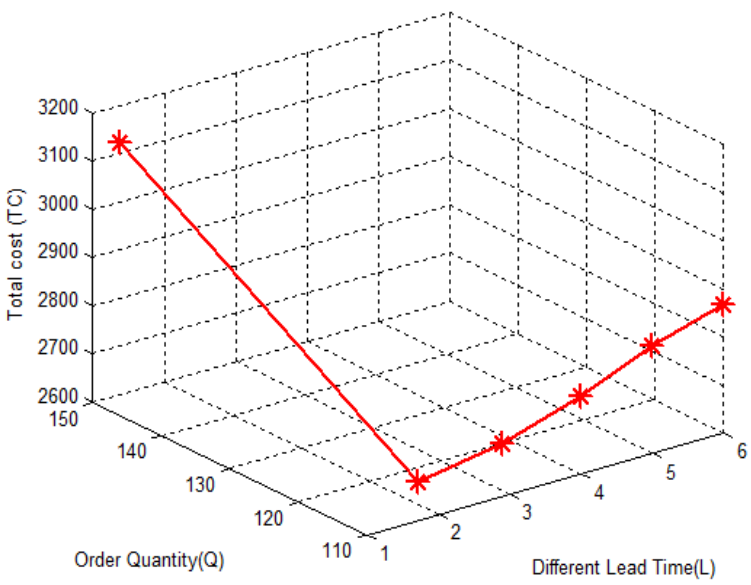

Figure (1) Graph representing the convexity of TC

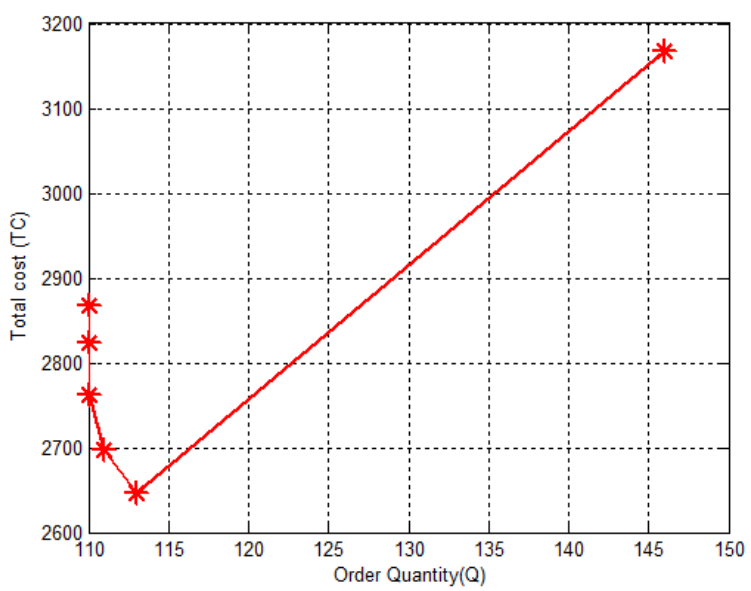

Figure (2) Graphical representation of the optimal solution in TC

\section{CONClusion}

Currently lead time is a fashionable tradition in mechanized systems in the inventory control and supply chain management. Lead time is a noteworthy factor in any inventory management scheme. A lead time is the latency between the start and finishing of a process. Traditional inventory models assumed that lead time is a constant or random variable which is not a controllable factor. However, in practice, lead time could be shortened by paying an additional crashing cost; in other words, it is controllable.

In a lot of realistic condition, lead time can be reduced by an extra crashing cost. That is, lead time is controllable. So in this article presents inventory models that consider order quantity and lead time as decision variables. Here we have used the lead-time crashing cost per order $R(L)$ is assumed to be an exponential function of $L$. A numerical example demonstrates the effectiveness of the developed model. The contribution of this article is developing a mathematical model and an effective solution procedure to find the optimal 
solution. Moreover, a numerical example is presented to illustrate the important issues related to the proposed models.

\section{APPENDIX}

$$
\frac{\partial T C(Q, L)}{\partial Q^{2}}=\frac{2 A D}{Q^{3}}+\frac{2 D e^{\frac{C}{L}}}{Q^{3}}>0
$$

\section{ACKNOWLEDGEMENT}

The authors wish to express their thankfulness to the editors and reviewers for their helpful suggestions and corrections to improve the clarity of the present paper. The first author research work is supported by DST INSPIRE Fellowship, Ministry of Science and Technology, Government of India under the grant no. DST/INSPIRE Fellowship/2011/413A dated 22.12.2015 and UGC-SAP, Department of Mathematics, The Gandhigram Rural Institute - Deemed University, Gandhigram - 624302, Tamilnadu, India.

\section{REFERENCES}

[1] Ballou, R. H. (2004). "Business Logistics/Supply Chain Management".

[2] Banerjee, A. (1986). “A joint economic-lot-size model for purchaser and vendor," Decision Sciences. Vol. 17, pp. 292-311.

[3] Ben-Daya, M. \& Raouf, A. (1994). "Inventory models involving lead time as decision variable", Journal of Operational Research Society. Vol. 45, pp. 579-582.

[4] Ben-Daya, M., \& Hariga, M. (2003). "Lead-time reduction in a stochastic inventory system with learning consideration", International Journal of Production Research. Vol. 41, pp. 571-579.

[5] Chang, H. M., Ouyang, L. Y., Wu, K .S. \& Ho., C. H. (2006). "Integrated vendor-buyer cooperative inventory models with controllable lead time and ordering cost reduction”, European Journal of Operational Research, Vol. 170, pp. 481-495.

[6] Chen, C. K., Chang, H. C. \& Ouyang, L. Y. (2001). "A continuous re- view inventory model with ordering cost dependent on lead time", International Journal of Information and Management Sciences. Vol. 12, pp. 1- 13.

[7] Cousins, P. D., Lawson, B. \& Squire, B. (2006). "Supply chain management: theory and practice the emergence of an academic discipline", International Journal of Operations \& Production Management, Vol. 26, pp.697 - 702.

[8] Finch, C. (2006). "Operations Now: Profitability, Processes, Performance”, 2nd edn, McGraw-Hill/ Irwin, United States.

[9] Ghare, P. M., \& Schrader, G. H. (1963) "A model for exponentially decaying inventory system", International Journal of Production Research, Vol. 21, pp. 449-460.

[10] Gholami-Qadikolaei, A., Sobhanallahi, M. A. \& Mirzazadeh, A. (2013). "Lead time reduction inbudget and storage space restricted lot size reorder point inventory models with controllable negative exponential backorder rate", Research Journal of Applied Sciences, Engineering and Technology, Vol.5, pp. 1557-1567.

[11] Goyal, S. K. \& Nebebe, F. (2000). "Determination of economic production-shipment policy for a single-vendor-single-buyer system", European Journal of the Operational Research. Vol. 121, No. 1, pp. $175-178$.

[12] Goyal, S. K. (1976). "An integrated inventory model for a single supplier-single customer problem". International Journal of Production Research. Vol. 15, pp. 107-111.

[13] Goyal, S. K. (1988). "A joint economic-lot-size model for purchaser and vendor: a comment," Decision Sciences. Vol. 19, pp. 236-241.

[14] Goyal, S. K. (1995). “A one vendor multi-buyer integrated inventory model: a comment", European Journal of Operational Research. Vol. 82, pp. 209-210. 
International Journal of Managing Value and Supply Chains (IJMVSC) Vol. 7, No. 2, June 2016

[15] Hariga, M. \& Ben-Daya, M. (1999). "Some stochastic inventory models with deterministic variable lead time”. European Journal of Operational Research. Vol. 113, pp. 42-51.

[16] Hariga, M. (1999). "A stochastic inventory model with lead time and lot size interaction", Production Planning and Control. Vol.10, pp. 434-438.

[17] Hill, R. M. (1997) "The single-vendor single-buyer integrated production inventory model with a generalized policy". European Journal of Operational Research. Vol. 97, No. 3, pp. 493-499.

[18] Hill, R. M. (1999) "The optimal production and shipment policy for the single-vendor single-buyer integrated production-inventory problem", International Journal of production Research. Vol. 37, pp. 2463-2475.

[19] Hsu, S. L. \& Lee, C.C. (2009). Replenishment and lead time decisions in manufacturer retailer chains, Transportation Research Part E, Vol.45, pp. 398-408.

[20] Lan, S. P., Chu, P., Chung, K. J., Wan, W. J. \& Lo, R. (1999). "A simple method to locate the optimal solution of the inventory model with variable lead time". Computers and Operations Research. Vol. 26, pp. 599-605.

[21] Lee, HL \& Billington, C 1995, 'The evolution of supply chain management models and practices at Hewlett Packard', Interface, Vol. 25, no.5, pp.42-63.

[22] Liao, C. J. \& Shyu, C. H. (1991). "An analytical determination of lead time with normal demand", International Journal of Operations \& Production Management. Vol. 11, pp.72-78.

[23] Lu, L. (1995). "A one- vendor multi-buyer integrated inventory model". European Journal of operational Research. Vol. 81, pp. 312-323.

[24] Martinich, J. C. (1997). "Production and Operations Management", Wiley, New York.

[25] Moon, I. \& Choi, S. (1998). "A note on lead time and distributional assumptions in continuous review inventory models", Computers and Operations Research. Vol. 25: pp. 1007-1012.

[26] Naddor, E. (1966). "Inventory Systems, John Wiley, New York".

[27] Ouyang, L. Y. \& Chang, H. C. (2001). "The variable lead time stochastic inventory model with a fuzzy backorder rate", Journal of the Operational Research Society of Japan. Vol. 44, pp.19-33.

[28] Ouyang, L. Y. \& Wu, K. S. (1997). "Mixture Inventory model involving variable lead time with a service level constraint", Computers and Operations Research. Vol. 24, pp. 875-882.

[29] Ouyang, L. Y. \& Wu, K. S. (1998). "A minimax distribution free procedure for mixed inventory model with variable lead time", International Journal of Production Economics. Vol. 56-57, pp. 511-516.

[30] Ouyang, L. Y. \& Wu, K. S. (1999). "Mixture inventory model involving variable lead time and defective units", Journal of Statistics and Management Systems. Vol. 2, pp.143-157.

[31] Ouyang, L. Y., Wu, K. S. \& Ho, C. H. (2004). "Integrated vendor-buyer cooperative model with stochastic demand in controllable lead time", International Journal of Production Economics. Vol. 92, pp. 255-266.

[32] Ouyang, L. Y., Yeh, N. C. \& Wu, K. S. (1996). "Mixture inventory model with backorders and lost sales for variable lead time", Journal of Operational Research Society. Vol. 47, pp. 829-832.

[33] Ouyang, L.Y. \& Wu, K. S. (1997). "Mixture inventory model involving variable lead time with a service level constraint”, Computers Operations Research, Vol. 24, pp. 875-882.

[34] Pan, C. H. \& Hsiao, Y. C. (2001). "Inventory models with backorder discount and variable lead time", International Journal of Systems Science. Vol. 32, pp. 925-929.

[35] Pan, J. C. H. \& Yang, J. S. (2002). "A study of an integrated inventory model with controllable lead time”, International Journal of Production Research. Vol. 40, pp. 1263-1273.

[36] Priyan, S. \& Uthayakumar, R. (2015). "Continuous review inventory model with controllable lead time, lost sales rate and order processing cost when the received quantity is uncertain", Journal of Manufacturing Systems, Vol. 34, pp. 23-33.

[37] Priyan, S. \& Uthayakumar. (2014). "Optimal inventory management strategies for pharmaceutical company and hospital supply chain in a fuzzy-stochastic environment" Operations Research for Health Care, Vol. 3, pp. 177-190.

[38] Sachan, A. \& Datta, S. (2005). "Review of supply chain management and logistics research", International Journal of Physical Distribution \& Logistics Management, Vol. 35, pp. 664 - 705.

[39] Sara, S., Parviz, F., Ali, A. \& Kia, P. (2013). "Integrated vendor-buyer cooperative inventory model with controllable lead time, ordering cost reduction, and service-level constraint", International Journal of Advanced Manufacture Technology, Vol. 65, pp. 657-666.

[40] Shukla, R. K., Garg, D. \& Agarwal, A. (2011). "understanding of supply chain: a literature review", International Journal of Engineering Science and Technology (IJEST) Vol. 3, pp. 2059-2072 
International Journal of Managing Value and Supply Chains (IJMVSC) Vol. 7, No. 2, June 2016

[41] Silver, E. A. \& Peterson, R. (1985) “Decision Systems for Inventory Management and Production Plannings", $2^{\text {nd }}$ Edition John Wiley, New York.

[42] Storey., Emberson, C., Godsell, J. \& Harrison, A. (2006). "Supply chain management: theory, practice and future challenges", International Journal of Operations \& Production Management, Vol. 26, pp. $754-774$

[43] Tersine, R. J. (1982). "Principles of Inventory and Materials Management", North Holland, New York.

[44] Vijayashree, M. \& Uthayakumar, R. (2015). "Integrated Inventory Model with Controllable Lead Time Involving Investment for Quality Improvement in Supply Chain System”. International Journal of Supply and Operations Management, Vol. 2, pp. 617-639.

[45] Vijayashree, M. \& Uthayakumar, R. (2015). "Two-Echelon Supply Chain Inventory Model with Controllable Lead Time", International Journal of Systems Assurance Engineering and Management. (DOI 10.1007/s13198-015-0346-6)

[46] Yang, J. S., Pan, J. C. H. (2004). Just-in-time purchasing: an integrated inventory model involving deterministic variable lead time and quality improvement investment, International Journal Production Research, Vol. 42, pp. 853-863.

[47] Yang, M. F. (2010). Supply chain integrated inventory model with present value and dependent crashing cost is polynomial. Mathematical and computer Modelling .51, 802-809.

\section{Biographical Notes}

M. Vijayashree is a full time research scholar in the Department of Mathematics at The Gandhigram Rural Institute - Deemed University, Gandhigram, India. She received her B.Sc in Mathematics from M.V.M Govt Women's Arts College, Dindigul, Tamilnadu, India in 2007 and M.Sc. Tech (IMCA) in Industrial Mathematics with Computer Applications from The Gandhigram Rural Institute-Deemed University, Gandhigrm, Dindigul, Tamilnadu, India in 2010. Currently, she is a Senior Research Fellow (SRF) under DST INSPIRE, New Delhi, in the Department of Mathematics, The Gandhigram Rural Institute - Deemed University, Gandhigram-624302, Dindigul, Tamilnadu, India. She has published about 7 papers in international and national journals. Her research interests include the following fields: Operations Research, Inventory Management and Control, Supply Chain Management.

R. Uthayakumar was born in Dindigul, Tamilnadu, India, in 1967. He received his B.Sc. degree in Mathematics from G.T.N. Arts College, Dindigul in 1987, M.Sc. degree in Mathematics from American College, Madurai in 1989, M.Phil., degree in Mathematics from Madurai Kamaraj University, Madurai in 1991, B.Ed. degree in Mathematics from Madurai Kamaraj University, Madurai in 1992 and Ph.D. degree in Mathematics from The Gandhigram Rural Institute - Deemed University, Gandhigram, India in 2000. Currently, he is professor of the Department of Mathematics at The Gandhigram Rural Institute - Deemed University, Gandhigram, India. He has published about 133 papers in International and National journals. His research interests include the following fields: Mathematical Modeling, Fractal Analysis, Operations Research, Inventory Management \& Control and Supply Chain Management. 